\title{
WIKI MODERATORS' CONTRIBUTIONS TO ENHANCE THE PEDAGOGICAL IMPLEMENTATION OF WIKI
}

\author{
NASHWA IsMAIL \\ nsei1e09@soton.ac.uk \\ University of Southampton, United Kingdom
}

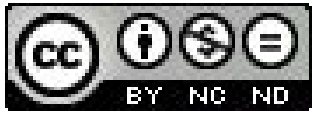

\begin{abstract}
Wiki has proved extensively that it is an innovative technology situated among other social network applications, because it enables its users to develop web content collaboratively, thereby making it open to all online users. The pedagogical use of Wiki is still in early stages; for this reason a lot of academic research has highlighted the lack of investigation into the pedagogical use of Wiki as a tool for collaborative learning. This paper investigates Wiki by focusing on its advantages and disadvantages for the learning process, while highlighting how Wiki moderators can contribute by embedding Wiki successfully into the learning process.
\end{abstract}

Key words: wiki, constructivism, pedagogy, collaboration, engagement, moderator

\section{INTRODUCTION}

In general, Mohamad and Klobas (2010) found that most young learners are captivated and motivated by social networking facilities of Web 2.0 like Facebook and Myspace. Therefore, using social software for learning can easily motivate these learners. West and West (2008) integrated social networks with learning and indicated that learners in the $21^{\text {st }}$ century prefer learning that supports participation and interaction, and which connects them to their peers - all of which can be done through the use of social networks. At the heart of the Web 2.0 applications lies specifically Wikipedia, which is a public Wiki where any user from anywhere can take part in sharing information (Chatfield, 2009).

The evidence of the successful use of Wiki is found in many areas, such as the storing of online books. In addition, companies like System Applications and Products (SAP), Motorola, or British Telecommunications utilise Wiki as corporate intranet (Ebersbach et al., 2008). In educational institutions like universities Wikis are widely used, for example Blackboard, they allow students to collaboratively design and implement websites as part of class content - they can perform these tasks from separate locations, at any time (Emory University, 2013; University of Southampton, 2013).

Notably, there is an obvious lack of research that investigates the pedagogical potential of Wiki and its capabilities to construct knowledge (Ruth, \& Houghton, 2009). For online teachers, who are sometimes also given the role of Wiki administrators and/or Wiki facilitators, online environment poses more challenges in their role as teachers. According to Bender (2003) and Anderson (1997), these challenges consist in, for example, the required technical skills and knowledge of on- 
line tools, the need to keep the learner motivated and to deal with online students while considering their individual differences with no physical presence. Counting all these challenges, teachers are asked to deliver an interactive, inspirational, exciting and challenging learning experience. However, there is a lack of research into the pedagogical application of Wiki and there are challenges regarding the role of Wiki teachers. As a result, educators are still far from considering Wiki as a tool of thinking, acting and co-constructing knowledge.

The main purpose of this paper is to discuss some of the criticism directed at Wiki. Moreover, how Wiki teachers can contribute to overcoming these obstacles, by clarifying some of the extra roles in online practices that are a part of a successful and professional application of Wiki. For the purpose of this paper, the terms "Wiki teacher", "Wiki administrator" and "Wiki moderator" will be used interchangeably. The reason behind the use of the term "moderator" is that a Wiki teacher is not just a facilitator of knowledge; rather, the Wiki moderator also incorporates other teaching practices to gain the optimal use of Wiki. These other teaching practices include collaboration between learners and their moderators, monitoring and tracking the learners' progress while applying Wiki, as well as rules and regulations.

To investigate the limitations of Wiki and how teachers can contribute to overcoming them, this paper will present the discussion in three sections. The first section will explain what exactly is meant by Wiki, and give an overview of its invention and beginnings. The second section will discuss the criticism directed towards Wiki, and the literature which contains this criticism. The third section will explore how teachers can contribute to a successful implementation of Wiki as a learning tool.

\section{WHAT IS WIKI?}

To be able to apply Wiki pedagogically and overcome its drawbacks, it is essential to understand the features and services of Wiki.

According to Mader (2008a), Wiki is a website that allows easy creation and editing of any number of interlinked web pages, via a web browser (figure 1).

Figure 1: The creation and modification of knowledge and information in Wiki. Source: Mader, 2008a.

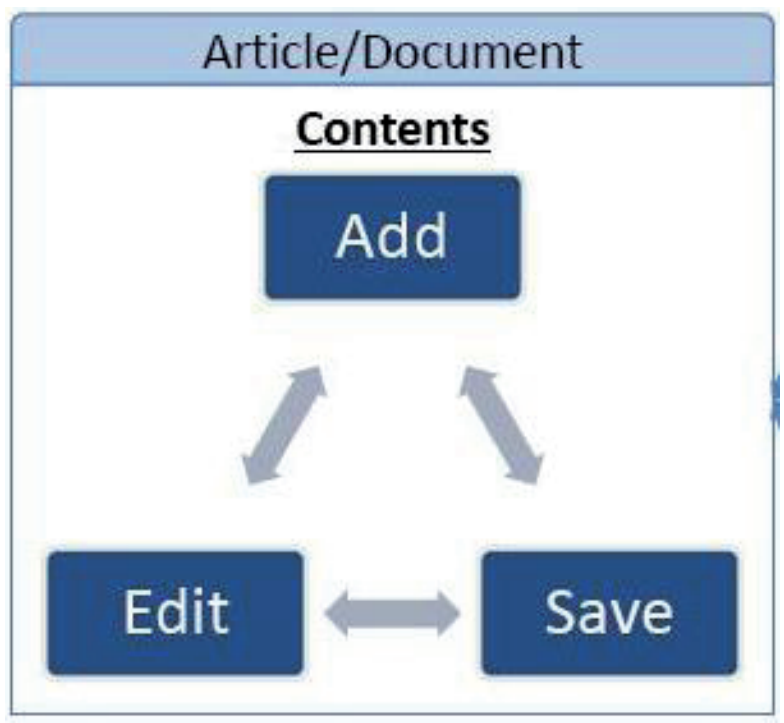


The first Wiki was invented by L. Leuf and W. Cunningham in the 1990s. It was first named "Wikiwikiweb" and later shortened to "Wiki" (Leuf, \& Cunningham, 2001). The word "wiki" is Hawaiian and means "fast" or "hurry". Wiki is an online collaborative software which has several significant features (Hinchcliffe, 2006; Ebersbach et al., 2008; Chatfield, 2009). Its content is fast and uncomplicated for end users as it is based on capturing and sharing content between all users. In addition, for teachers it is successful in monitoring complex tasks, tracking memos, creating plans and providing a powerful resource of knowledge. Wiki also extends page length, as most have no page limit, unlike other mail servers which have restrictions on the number of web pages. Lindsay (2009) explained more extended features of Wiki, such as:

- the ability to embed multimedia into a Wiki, e.g. videos, Really Simple Syndication (RSS), images, etc.;

- history tab to show all edits on the page; Ebersbach et al. (2008) added that this is a very useful feature to roll back to the first version in case of any destructive editing activity of unfriendly users; Mader (2008b) stressed that revising history in Wiki is essential to keep full track of who and when contributed information and what information they contributed, changed or removed;

- versioning system - it was defined by Woods and Thoeny (2007) as "saving a version on each wiki page so that previous versions can be referred to or stored" (Woods and Thoeny, 2007, p. 16); Mader (2008b) explained the benefit of using the versioning feature for storage to save the history of each page and re-establishing previous changes if needed;

- notify me tab - this allows the user to be updated via e-mail about any changes on the page;

- search feature;

- tagging feature to facilitate gathering pages;

- print options (Woods and Thoeny, 2007);

- change alerts - this allows Wiki administrators to be notified, monitor and track any changes on any page (Chatfield, 2009);

- back links - these are used to demonstrate how every page is connected with another in a Wiki.

In general, educators can harness Wiki in diverse applications, such as implying course content, organising schedules, attaching related files and following up students' brainstorms. This helps to identify any possible obstacles in the students' learning process as early as possible, alleviate actual assessment and facilitate the collaborative brainstorming of ideas. These features provide Wiki with the flexibility to be applied in many fields and different activities. Figure 2 illustrates the various Wiki uses according to a survey conducted in 2008.

From the author's point of view, there are two main issues to be highlighted. Firstly, the features of Wiki provide a collaboration of knowledge, where each user can take part in creating and sharing information. This concept is in line with Vygotsky's notion (1978) where each person can learn if they join knowledge communities. All the above mentioned features mean that Wiki is to be highly recom- 
mended for closed communities, such as schools and colleges. Secondly, Wiki is simple to use as an application compared to other social network applications. However, technophobics and young learners, who do not own the fundamental basics to deal with technology, may find it more challenging. In this case, technical experience of the moderator and end users training are necessary.

\section{How do you use a wiki?}
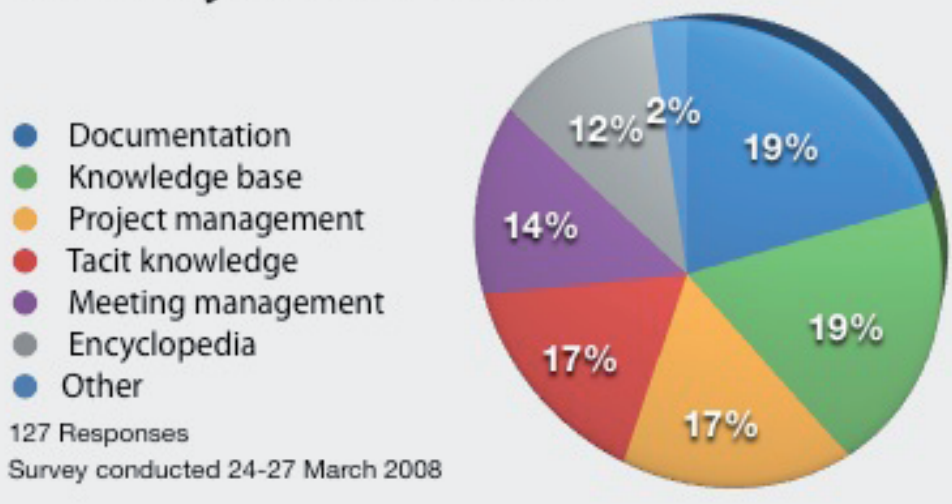

\section{Grow YourWiki www.ikiw.org}

Figure 2: Different uses of Wiki.

Source: Mader, 2008a.

Having reviewed the invention of Wiki and its technical features, the following section will more deeply discuss the pedagogical perspective of Wiki by exploring the literature that critically analyses Wiki.

\section{WIKI'S LIMITATIONS IN EDUCATION}

This section will focus on the three main areas of the criticism of Wiki. The first is the unstandardised structure of Wiki, which leads to disorientation among learners. The second section will explore the view of some anti-constructivist literature which suggests Wiki is not the optimal approach in the case of learners with no prior knowledge. Finally, it has been suggested that Wiki is weak in supporting a Personal Learning Environment (PLE).

Conklin (1987) explained disorientation as "the loss of sense of location and direction in a non-linear document," and points out that online learning (OL) has a high tendency to make its users feel disoriented. This leads to their disengagement from the learning environment including peers, teachers and content, ending with frustration and loss of interest in learning. Applying this claim to Wikis, Carroll (2000) reported that although there is an increasing success in the use of Wiki in 
leaning, it does not show a high success in particular subjects such as Math and Computer Science. Again, this is because of the users' confusion and their cognitive overload by multiple sources in online resources. Woods and Thoeny (2007) suggested that the reason behind this disorientation in Wiki is its generic and broad definition, as a collection of web pages that any user can edit. Woods and Thoeny (2007) claim that Wikis are built-up by practice only, without being officially standardised or assigned a clear purpose for the software. In detail, Wiki follows neither content management systems released by professional programmers, nor web publishing tool standards which both educators and learners can follow. This is claimed to be one of the reasons for learner disorientation and avoidance of using Wiki in learning.

Defending against this argument, Zittrain (2009) and Mitchell (2007) point out two main issues; firstly with regard to the Wiki users themselves, they are all a part of a social system with overlapped and common goals. Secondly, with regard to the Wiki structure itself, it has a generic inherent structure where each user can edit the contents freely, create relationships and establish links between the web pages. From the author's point of view, this has two benefits. For one, it manipulates users' productive challenges to be more creative and innovative. According to Booth (2009), after some time Wiki learners find themselves becoming experts, and they may introduce new information to the learning community, including peers and teachers. Another reason Wiki's unstandardised nature increases its flexibility and ability to be applied to various fields and disciplines. Arguably, this is better than working with centralised regulations which serve only specific subjects.

Another point of interest is that of Wiki as an appropriate learning tool for constructivism. Constructivism is a theory which argues that humans generate knowledge and learning from their experiences (Vygotsky 1978). Kirschner et al. (2006) criticised the central claims of constructivism and question its effectiveness for novice learners with no or little prior knowledge, adding that the need for structured and organized learning activities is vital. For example, they described constructivist teaching methods as "unguided methods of instruction". In contrast, a guided method of instruction is, for example, a teacher teaching experience to pass a test, providing revision notes and practice tests. Ruth and Houghton (2009) argue against this concept, explaining that this spectrum of view is extremely narrow, because it creates students who compete to only achieve the highest score and pass a test, rather than compare and contrast their knowledge to make sharable knowledge. This insight highlights the lack of deep understanding of constructivism and its benefit for learning. According to Vygotsky (1978), constructivism requires the novice student to search a problem space through navigating in the problem-relevant information, and to find the essential information to solve the presented problem. However, the current dominant tendency in education is to promote active and collaborative learning; Vygotsky (1978) claims that collaboration is a basic human activity for learning. Many years after the publication of his work, Lipponen (2002) merged the idea of collaboration with technology as a process of knowledge which implies participation between individuals. This is because of the digital revolution in the years since Vygotsky, communication and infor- 
mation technology enhancements can contribute to creating, sharing and capturing this social knowledge to produce a collaborative system known as Computer Supported Collaborative Learning (CSCL) (Lipponen, 2002). Considering all these ideas, we can conclude that Wiki is a socially oriented application which provides an optimal collaborative learning approach.

The final argument regarding Wiki will focus on its doubtful contribution to the PLE. Ruggieri (2006) defined PLE as a combination of self-initiated learning, where the learner takes the decision to learn, and self-directed learning, where the learner decides what to learn and selects the method to achieve the learning aims. With regard to the personal aspect, Parker and Chao (2007) differentiate between Wikis and blogs, by suggesting that Wikis are a collaborative authoring application, while a blog is more directed towards personal authoring. In my view, blogs as a learning method would encourage the learner's innovation and creativity. However, there are issues regarding the social perspective of learning, since it may lead to a student's isolation and individuality. Personal learning can be achieved by using blogs as a social learning application, however the limitation of blogs may drive some of the sociability out of the learning process if care is not taken to emphasise the importance of peers in learning. Thus, the use of Wiki in learning encourages peer-to-peer interaction and matches the approach of social constructivism. It may not be as efficient as a tool in PLE as the learner may not be fully self-directed or self-initiated.

Having discussed in detail the three main points of criticism directed at Wikis on the pedagogical level, the following section will highlight how Wiki teachers can help overcome the drawbacks of Wiki and implement it successfully as a learning tool.

\section{THE WIKI MODERATOR/TEACHER}

This section focuses on the Wiki administrators, who are likely to be the teachers; detailing the potential roles they can provide to overcome the limitations of Wikis.

Wiki is a new innovative technology which demands navigating in various sources of knowledge. When first using Wikis, some challenges are to be expected; it may be considered a complicated task for less technologically skilled users, which may cause users to give-up after using it for the first time. For that reason, Chatfield (2009) focused on the vital role of the administrator, especially in small communities such as schools and colleges. He warned against expectations that a Wiki will flourish and attract contributors immediately after setting it up. Teachers themselves should be supporting their learners to be involved, energetic and always available to communicate with individual Wiki users, and not only focus on increasing their Wiki users.

To gain maximum benefit from Wiki there is a particular technical feature which has a positive impact on its pedagogical benefits, namely the WikiTrail. This feature allows the Wiki author to follow the sequence of opened links, thus creating a trail through these pages (WikiTrails, 2012). Each trail represents the 
links visited by the user within the Wiki, so the WikiTrail provides the author with a chronological history of their visited links. This feature is very much in line with the Zone of Proximal Development (ZPD) established by Vygotsky (1978), a model which illustrates the distance between the learner's actual development level and the learner's potential development under adult guidance or in collaboration with more capable peers. Tracking the visited links in a Wiki through a WikiTrail will provide teachers with the information on where a learner started and where they are going. Additionally, it enables teachers to work more closely to the learners' level of potential development, rather than their level of actual development.

To counteract the limitations of Wiki in PLE, in comparison to blogs, teachers must be encouraged to incorporate more than one type of social networking model, thereby gaining the optimal use of social network applications in learning. In addition to all the previous considerations for Wiki teachers, they are required to stay updated with technology, be informed of different applications of social networks, identify the advantages and disadvantages of each, and try to integrate them into their learning practices.

\section{CONCLUSION}

In summary, Wiki has a lot of potential for successful collaborative online learning. It has a strong emphasis on the social perspective of learning, which has been supported by Vygotsky (1978), through promoting engagement and interaction between student peers and teachers.

Although the literature and empirical evidence indicate that Wikis have the ability to construct and share learners' knowledge, they also provide the space for communities of discourse and knowledge to grow. Moreover, Wikis are remarkably still not fully implemented in the educational arena.

This paper has investigated some of the drawbacks of Wiki and discussed how online teachers can help overcome these limitations, and therefore enhance the use of Wiki in learning. Wiki moderators are likely to give attention to some initial pedagogical basics of Wiki to get its optimal use in learning, such as learners' privacy or learners' focused orientation. This would help users to maintain motivation and reduce frustration associated with disorientation. Although Wikis are able to create a rich collaborative learning atmosphere in the classroom, if educators are not technologically updated and work against collaborative social network practices, Wikis will not be implemented successfully in learning.

\section{REFERENCES}

Anderson, J. (1997). Social work with groups: a process model. New York: Longman.

Bender, T. (2003). Discussion based online teaching to enhance student learning: Theory, practice and assessment. Sterling, VA: Stylus.

Booth, D. (2009). Whatever Happened to Language Arts? ...It's Alive and Well and Part of Successful Literacy Classrooms Everywhere. Kanada: Pembrok Publishers.

Carroll, J. M. (2000). Making use: Scenario-based design of human-computer interactions. Cambridge, Massachusetts: MIT Press. 
Chatfield, T . B. (2009). The Complete Guide to Wikis: How to Set Up, Use, and Benefit from Wikis for Teachers, Business Professional, Families and Friends. Ocala, Fla: Atlantic Pub. Group.

Conklin, J. (1987). Hypertext: An introduction and survey. IEEE Computer, 7, 17-41.

Ebersbach, A., Glaser, M., Heigl., R., Warta, A. (2008). Wiki: Web Collaboration. 2nd Ed. Berlin: Springer.

Emory University (2013). Welcome to the Discussions Resources Wiki!. Retrieved from http://emorydisc.wikispaces.com/

Hinchliffe, D. (2006). Blogs, wikis, and Web 2.0 as the next application platform. Retrieved from http:/ / www.zdnet.com/blog/hinchcliffe/blogs-wikis-and-web-20-as-the-next-application-platform/50

Kirschner, P. A., Sweller, J., \& Clark, R. E. (2006). Why minimal guidance during instruction does not work: an analysis of the failure of constructivist, discovery, problem-based, experiential, and inquiry-based teaching. Educational Psychologist, 2, 75-86.

Leuf , L., \& Cunningham, W. (2001). The Wiki Way: Quick Collaboration on the Web. Boston: Addison-Wesely.

Lindsay, J. (2009). Web 2.0 and Learning. Retrieved from http://julielindsay.wikispaces.com/ Web2+and+Learning

Lipponen, L. (2002), Exploring foundations for computer-supported collaborative learning, CSCL 2002. [Online] Available at: http://newmedia.colorado.edu/cscl/31.html (Accessed: 12/07/2012)

Mader, S. (2008a). What is a wiki and how does it work?. Retrieved from http://kibesa.wikispaces. com/Definition+of $+a+$ wiki

Mader, S. (2008b). How do you use a wiki? Poll results. Retrieved from http://blogs.atlassian.com/ news/2008/03/how_do_you_use.html

Michelle, S. (2008). Easy Wiki Hosting, Scott Hanselman's blog, and Snagging Screens. MSDN Magazine. Retrieved from http://msdn.microsoft.com/en-us/magazine/cc700339.aspx

Mohamad Nordin, N., Klobas, J. (2010). Wikis as collaborative learning tools for knowledge sharing: Shifting the education landscape, [in:] Z. Abas et al. (eds.), Proceedings of Global Learn 2010 (pp. 331-340). AACE.

Parker, K. R., Chao, J. T. (2007). Wiki as a Teaching Tool. Interdisciplinary Journal of Knowledge and Learning Objects, 3, 57-72.

Ruggieri, W. (2006). Personal Learning: The Key to Better Health, Greater Wealth, And Increasing Wisdom. USA: Booklocker, Inc.

Ruth, R., Houghton, L. (2009). The wiki way of learning' Australasian. Journal of Educational Technology, $2,135-152$.

University of Southampton (2013). Using Wikis Within Blackboard. Retrieved from http://www. southampton.ac.uk/isolutions/computing/elearn/Wikis/index.html

Vygotsky, L. S. (1978). Mind in Society. The Development of Higher Psychological Processes. London: Harvard University Press.

West, J., West, M. (2009). Using wikis for online collaboration: The power of the read-write web. San Francisco: Jossey-Bass.

Wikitrails (2012). WIKITRAILS. Retrieved from http:/ / meta.wikimedia.org

Woods, D., Thoeny, P. (2007). Wikis for Dummies. Hoboken, NJ: Wiley Publishing.

Zittrain, J. (2009). The Future of the Internet - and How to Stop It. Yale University Press \& Penguin UK. 